ministrative responsibility would be bestowed on the developing countries themselves, while overall responsibility would rest with the UN general assembly. points are likely to occupy much of the time up to the Vienna conference. Meanwhile, in an attempt to make sure that something of a more immediately practical nature emerges from UNCSTD, various countries are sup-
Detailed discussion on these various

porting proposals that specific efforts should be made to establish projects in areas requiring greater research. Belgium, for example, submitted a resolution to the preparatory committee last week suggesting five areas for international collaborative research: solar energy, rural development technologies, tropical diseases, methods of increasing food production, and an inventory of natural resources.

David Dickson

\section{Agricultural research centres transformed}

THE dozen international agricultural research centres set up between 1959 and 1976 to conduct research into problems of tropical agriculture have had considerable influence on the national research systems of many developing countries as well as on the crops and methods used by farmers. The very changes the international centres have stimulated, however, have in turn resulted in changes being made to the mode of operation of the centres themselves so that they are no longer working to the rules laid down when the first, the International Rice Research Institute, was set up twenty years ago.

Speaking to a small gathering at the Science Policy Research Unit, University of Sussex last week, Dr Edward Clay of the university's School of African and Asian Studies said that the international centres had greatly influenced the way scientists in third world countries "perceive the research they're to carry out". In particular ever since IRRI and the International Center for the Improvement of Maize and Wheat (CIMMYT), the first two centres to be set up, achieved considerable success in breeding highyielding dwarf varieties, most research on increasing yields for all sorts of crops in many countries has centred on finding dwarf varieties.

In India, for example, rice research has tended to focus on light-yielding semi-dwarfs for irrigated land. $67 \%$ of rice breeding is oriented towards irrigated rice, even though only $28 \%$ of the land used for rice cultivation is irrigated. And almost all the new varieties developed have been semidwarfs. Only 5\% are suited for deep water although $40 \%$ of the land used for rice growing is under deep water.

According to Dr Clay, the international centres cannot be held entirely responsible for this mismatch of research to needs although it is highly likely that they have had some influence. In the case of rice research, for example, IRRI has mainly concentrated on irrigated rice-simply because of the local conditions around its home in the Philippines.

The centres' influence, however, claims Dr Clay, extends beyond the individual scientist to the very agricultural policy of developing countries. "Experts were put into the international centres and were successful", he says "therefore the model of a centre was seen as a good recipe for success". More international centres were built and individual countries began to build their own single purpose centres. The Bangladesh government, for example, decided to create one specific rice research institute-"very large, costly and capital intensive with well-trained scientists". This was a new idea for an individual country-even countries with a highly organised research effort such as the US and Japan had not concentrated their research on just one topic into one place.

When IRRI and CIMMYT were first set up, they were intended to be solely research centres where Western scientists could apply certain techniques which had proved beneficial in agricultural research for temperate zone crops to tropical crops. As the spread, however, and individual developing countries began to take up their methods, they have played an increasing role in educating third world scientists and organising exchanges. With the creation of the Consultative Group for International Agricultural Research (CGIAR) "to raise funds and establish research policies" for the centres and the creation of more centres in different parts of the world, their operation has gradually become more bureaucratic.

"We now have well-defined bureaucratised institutions", according to Dr Clay. "This was not true of the original centres. In expanding and replicating the original model we've now got something quite different". There is now pressure for the centres to work much more with developing countries than was initially intended. And, according to Dr Clay, as they are essentially funded by industrialised countries this has put them into a complicated relationship between the aid-donors and their recipients.

Judy Redfearn influence of these first two centres

\section{Pre-UNCSTD colloquium planned}

Preparatrons ror the Colloquium on "Science, Technology, and Society" to be held by the UN Committee on the Application of Science and Technology to Development (ACAST) in Vienna next August immediately before UNCSTD, were the main item on ACAST's agenda when it met in Geneva recently. At the Colloquium 200 invited representatives of the world scientific and technological community will help formulate a document for discussion at UNCSTD.

During the first week of the ACAST meeting it became apparent that the Colloquium is seen only in terms of certain items of the agenda of UNCSTD. For whatever reasons, the members of ACAST seem to have forgotten their hitherto jealously guarded role as an independent advisory committee, and limited themselves mainly to points they had been asked to consider by UNCSTD Secretary-General, José da Costa.

However, da Costa himself possibly helped to harden ACAST's attitude. His personal intervention on a flying visit, during which he did not even stop to answer many of the questions he inspired, appeared to reflect considerable pessimism as to the outcome of his own Conference. Seeing less than a fifty-fifty chance of any concrete results, he feared it would be only a "conference verbale", within which ideas on, amongst other things, new forms of cooperation between North and South, as well as within the South might at best appear in the form of recommendations.

Da Costa's statement was also noteworthy for a sudden and highly emotional attack on the way in which his conference is being treated by the media, in particular by the "Lund Letter", published by an internationally-oriented group in Sweden, and which he singled out as "nordique et paranoiaque".

A second factor which further enlivened the ACAST proceedings was what looked remarkably like an attempt on the part of UNESCO, through their representatives at the meeting, to take over the whole Colloquium, albeit still disguised as an ACAST-sponsored meeting. Whether this was because of their frustration at the admittedly somewhat tardy and, to some observers, impractical way in which the Colloquium was being planned and organised, is not clear.

However, here the members of ACAST closed their ranks and refused to be stampeded by UNESCO's probably justified calls for urgency. 